J.B.METZLER 


\section{Metzler Lexikon Theatertheorie}

Herausgegeben von Erika Fischer-Lichte,

Doris Kolesch und Matthias Warstat

Verlag J. B. Metzler

Stuttgart - Weimar 
Inhalt

Vorwort

Liste der Einträge

Artikel A-Z

Mitarbeiterinnen und Mitarbeiter
S. V

S. VII

S. 1

S. 400

\section{Die Herausgeber/innen}

Erika Fischer-Lichte ist Professorin am Institut für Theaterwissenschaft der FU Berlin, Sprecherin des Sonderforschungsbereiches »Kulturen des Performativen « und des Graduiertenkollegs »Körperinszenierungen«, Leiterin des Interdisziplinären Zentrums für Kunstwissenschaften und Ästhetik sowie Mitglied der Academia Europaea, der Akademie der Wissenschaften zu Göttingen und der Berlin-Brandenburgischen Akademie der Wissenschaften.

Doris Kolesch ist Professorin am Institut für Theaterwissenschaft der FU Berlin, Projektleiterin im Sonderforschungsbereich »Kulturen des Performativen « und Mitglied der Jungen Akademie an der Berlin-Brandenburgischen Akademie der Wissenschaften.

Matthias Warstat ist Wissenschaftlicher Assistent am Institut für Theaterwissenschaft der FU Berlin und Mitarbeiter des Sonderforschungsbereichs »Ästhetische Erfahrung im Zeichen der Entgrenzung der Künste«.

Bibliografische Information Der Deutschen Bibliothek

Die Deutsche Bibliothek verzeichnet diese Publikation in der Deutschen Nationalbibliografie; detaillierte bibliografische Daten sind im Internet über <http://dnb.ddb.de> abrufbar.

ISBN 978-3-476-01956-1

ISBN 978-3-476-00035-4 (eBook)

DOI 10.1007/978-3-476-00035-4

Dieses Werk einschließlich aller seiner Teile ist urheberrechtlich geschützt. Jede Verwertung außerhalb der engen Grenzen des Urheberrechtsgesetzes ist ohne Zustimmung des Verlages unzulässig und strafbar. Das gilt insbesondere für Vervielfältigungen, Übersetzungen, Mikroverfilmungen und die Einspeicherung und Verarbeitung in elektronischen Systemen.

(C) 2005 Springer-Verlag GmbH Deutschland

Ursprünglich erschienen bei J.B. Metzlersche Verlagsbuchhandlung

und Carl Ernst Poeschel Verlag GmbH in Stuttgart 2005

www.metzlerverlag.de

info@metzlerverlag.de 


\section{Vorwort}

Das vorliegende Lexikon theatertheoretischer Begriffe ist kein Theaterlexikon im herkömmlichen Sinne. In ihm finden sich nicht die $\mathrm{Na}$ men von Theaterpraktikern und -theoretikern mit nachfolgender Kurzcharakteristik ihrer bedeutendsten Theaterarbeiten und/oder Konzepte. Es handelt sich auch nicht um ein Lexikon von Theaterbegriffen. Gängige Termini wie Kostüm, Schnürboden, Probe oder Inspizient wird man vergebens suchen. In das Lexikon sind vielmehr nur solche Begriffe aufgenommen, die als theoretisch bzw. theoriefähig gelten. Das wichtigste Kriterium für die Auswahl der Lemmata stellte der Anspruch dar, mit ihnen insgesamt einen Überblick über den heutigen Stand der Theoriediskussion in der Theaterwissenschaft zu ermöglichen. Daraus erklärt sich, weshalb Begriffe, die entweder für die heutige Diskussion kaum mehr relevant sind oder gerade erst auftauchen und noch keine klar erkennbaren Konturen besitzen, nicht in das Lexikon aufgenommen wurden. Da der Verlag eine deutliche Beschränkung hinsichtlich des Umfangs vorgegeben hatte, sahen wir uns vor die Entscheidung gestellt, entweder möglichst alle theoretischen oder theoriefähigen Theaterbegriffe mit relativ kurzen Artikeln darzustellen oder uns im Sinne des oben genannten Anspruchs zu beschränken, so dass es möglich war, uns für die heutige Diskussion besonders wichtig erscheinende Begriffe ausführlicher zu erläutern. Wir haben uns aus guten Gründen für die zweite Alternative entschieden. Denn das Lexikon ist als ein Studienbuch konzipiert, das imstande sein soll, seine Leserinnen und Leser in heutige Theoriedebatten einzuführen. Wieweit es diesem Anspruch gerecht $\mathrm{zu}$ werden vermag, werden seine künftigen $\mathrm{Be}-$ nutzer - Studierende, Promovierende, Wissenschaftlerinnen und Wissenschaftler sowie alle an der Theoriediskussion Interessierte entscheiden.

Wir danken dem J.B. Metzler Verlag und insbesondere Frau Ute Hechtfischer, die das Unternehmen in hervorragender Weise betreut hat. Zwar hat sie immer wieder Verständnis und Geduld gezeigt, wenn sich die Abgabe einzelner Artikel wieder einmal - wenn auch aus guten Gründen - verzögerte. Gleichwohl hat ihr nicht nachlassender freundlicher, aber energischer Druck nicht unwesentlich dazu beigetragen, dass das Unternehmen insgesamt doch in einer erfreulich kurzen Zeit realisiert werden konnte.

Berlin, im Juli 2005

Erika Fischer-Lichte, Doris Kolesch, Matthias Warstat 


\section{Liste der Einträge}

Affekt $\rtimes$ Gefühl

Akteur $\rtimes$ Schauspieler

Aktion

Apollinisch/Dionysisch

Ästhetik

Atmosphäre

Aufführung

Ausdruck $\uparrow$ Darstellung

Autbentizität $\gg$ Natürlichkeit

Avantgarde

Ballett $\uparrow$ Tanz

Bedeutung

Bewegung

Bild

Biomechanik $\rtimes$ Schauspieltheorie

Bübne ` Raum

Charakter

Chor

Choreographie

cultural performance $\gg$ Performance

Darstellung

Dekonstruktion

Dialog/Monolog

Dionysisch 7 Apollinisch/Dionysisch

Drama/Dramentheorie

dramatis personae $\uparrow$ Figur

Dramaturgie

Einfühlung

Emergenz

Energie

Entertainment $\rtimes$ Unterhaltung

Episches Theater

Ereignis

Erfahrung, ästhetische

Event $\gg$ Ereignis

Experiment $\uparrow$ Avantgarde

Fest

Figur

Fiktion

Gattungstheorie

Gedächtnis

Gefühl

Gender Performance

Gesamtkunstwerk
Gesangstheorien $>$ Singstimme/Gesangs-

theorien

Geste/Gestus

Handlung

Happening $\rtimes$ Aktion, Performance

Illusion

Imagination

Improvisation

Inszenierung

Interaktion

Interkulturalität

Intermedialität

Ironie

Katharsis

Komisches

Kommunikation

Körperlichkeit

Leidenschaft 7 Gefühl

Liminalität

Liveness

Marionette

Maske/Maskerade

Materialität

Medialität

Meta-Theater

Mimesis

Mimik $\$ Geste/Gestus

Monolog 7 Dialog/Monolog

Montage

Musik

Mythos

Narration

Natürlichkeit

Norm

Öffentlichkeit

Oper

Pathos $\uparrow$ Gefühl

Performance

Performativität/performativ

Person/Persona $\rtimes$ Figur

Perspektive $\rtimes$ Raum

Politisches Theater 
Postdramatisches Theater

Postkoloniales Theater

Präsenz

Prozessualität $\gg$ Performativität

Publikum

Raum

Regie $\rtimes$ Inszenierung

Regisseur $\rtimes$ Inszenierung

Repräsentation

Rezeption $\rtimes$ Wahrnehmung

Rhythmus

Ritual

Rolle

Schauspieler

Schauspieltheorie

Schein

Semiotik

Singstimme/Gesangstheorien

Situation

Spiel

Stil

Stimmlichkeit

Szene

Szenographie

Tableau vivant

Tanz
Textualität

Theateranthropologie

Theaterbegriffe

Theaterhistoriographie

Theaterikonographie

Theaterpädagogik/Theatertherapie

Theaterwissenschaft

Theatralität

Tragik

Transformation

Travestie

Unterhaltung

Verfremdung

Verkörperung

vierte Wand $\nearrow$ Raum

Virtuosität

Wahrnehmung

Werk

Wirklichkeit

Wirkung

Zeichen $\rtimes$ Semiotik

Zeit

Zeremonie $\rtimes$ Ritual

Zuschauer $\rtimes$ Publikum 